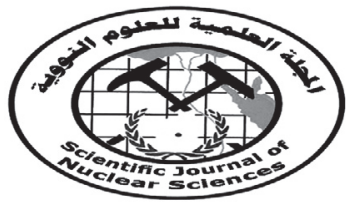

Nuclear Materials Authority

P.O.Box 530 Maadi, Cairo, Egypt
ISSN 2314-5609

Nuclear Sciences Scientific Journal vol. 1 , p $155-165$

2012

\title{
MICROBIAL LEACHING OF SOME VALUABLE ELEMENTS FROM EGYPTIAN PHOSPHATE ROCK
}

\author{
HESHAM M. KAMAL, HEBA M. A. MAHDY' ${ }^{1}$ RAIFA A. HASSANEIN, KHALID F. \\ MAHMOUD $^{1}$ and MOHAMED A. ABOUZEID ${ }^{2}$
}

Nuclear Materials Authority, POB 530 Maadi, Cairo, Egypt; Botany Department, Faculty of Science, Ain Shams University, 11566 Abbassia, Cairo, Egypt ${ }^{1}$; Microbiology Department, Faculty of Science, Ain Shams University, 11566 Abbassia, Cairo, Egypt ${ }^{2}$

\begin{abstract}
Four phosphate rock samples representing different phosphate mineralization modes in Egypt were selected from Abu Tartur, Nile valley and Red sea areas. Factors affecting the phosphate rock solubilization and some of the contained valuable elements by Aspergillus niger, Penicillium sp. and Pseudomonas fluorescence, were studied with especial orientation towards the completion of phosphate rock samples solubilization especially the low grade one. Effect of nitrogen source type on leaching efficiency by Aspergillus niger when two nitrogen sources on the phosphate bioleaching efficiency, it is clear that the ammonium chloride is more favorable as nitrogen source than sodium nitrate in the bioleaching of phosphate rocks. When Aspergillus niger was applied under the following conditions: $50 \mathrm{~g} / 1$ of sucrose as a carbon source, $0.1 \mathrm{~N}$ of ammonium chloride as a nitrogen source, 10 days incubation period, $0.5 \%$ solid: liquid ratio for $\mathrm{P}_{2} \mathrm{O}_{5}$ and $5 \%$ for $\mathrm{U}$ and REE and -270 mesh of grain size. The optimum leaching of $\mathrm{P}_{2} \mathrm{O}_{5}$, $\mathrm{U}$ and REE from phosphate rock samples reached $(23.27 \%, 17.4 \%, 11.4 \%$, respectively), while at -60 mesh they reached to $16.58 \%, 28.9 \%, 30.2 \%$ respectively. The optimum conditions for the maximal leaching efficiencies of $\mathrm{P}_{2} \mathrm{O}_{5}, \mathrm{U}$ and REE when applying the Penicillium $s p$. from the phosphate rock samples were: $100 \mathrm{~g} / 1$ of sucrose as a carbon source for $\mathrm{P}_{2} \mathrm{O}_{5}$ and $\mathrm{U}$ and $10 \mathrm{~g} / \mathrm{l}$ for REE, 7,15 and 10 days incubation period for $\mathrm{P}_{2} \mathrm{O}_{5}, \mathrm{U}$ and REE, respectively, $0.5 \%$ solid: liquid ratio for $\mathrm{P}_{2} \mathrm{O}_{5}$ and $5 \%$ for $\mathrm{U}$ and REE. Finally, the application of phosphate rock samples grinded to -270 mesh of grain size for $\mathrm{P}_{2} \mathrm{O}_{5}$ and (-60 to -140$)$ for $\mathrm{U}$ and REE. The studied leaching efficiency of $\mathrm{P}_{2} \mathrm{O}_{5}, \mathrm{U}$ and REE gave at -270 mesh $33.66 \%, 24.3 \%$, $15.9 \%$ respectively, while at -60 mesh they gave $33.76 \%, 26.7 \%, 17.8 \%$ and at -140 mesh gave $31.32 \%$, $27.9 \%, 17.6 \%$, respectively. The optimum conditions for the $\mathrm{P}_{2} \mathrm{O}_{5}$ leaching efficiency when applying the Pseudomonas fluorescence were: $10 \mathrm{~g} / \mathrm{l}$ of beef extract, 10 days incubation period, $0.5 \%$ solid: liquid ratio and -270 mesh of grain size reaching $79.35 \%$. The same behavior was traced for both U and REE leaching efficiencies thus they reached $57.4 \%$ and $37.6 \%$, respectively. While the attained results showed that the non sterilized rock is more favorable and the addition of phosphate rock after the incubation of organism for 4 days gave the higher efficiency than the addition of rock at the beginning of experiment.
\end{abstract}

\section{INTRODUCTION}

Nuclear energy shares nowadays with about $20 \%$ in the total world energy production even if exposing to a lot of criticisms from the green parties all over the world. Uranium has become a widely used source for nuclear energy and is considered the main fuel, starting with exploration, mining of uranium ore 
rocks, and milling the uranium ore materials to reproduce the base material for the uranium fuel cycle (Abd El-Latif, 1998). Uranium resources in Egypt can be classified into two main classes namely: the conventional (mined and milled basically as the main product for uranium) and the non-conventional (uranium production as a by-product). The Nuclear Materials Authority (NMA) has actually discovered seven conventional uranium resources in various Egyptian territories in the Eastern Desert and Sinai Peninsula. The Egyptian phosphate reserves are estimated by about 1.3 billion tons while the geological reserves reach 3000 million tons (Mahdy, 2009). The average assay of uranium in the Egyptian phosphate ores is $60 \mathrm{ppm}$, consequently, the phosphate assured reserves are estimated to contain about 40.000 tons uranium at least (NMA Internal report, 1992). Leaching of phosphate rock means mainly the dissolution of some strategic and economic rare metals such as fluorine, iron and phosphorus. The later is used in nearly $50 \%$ of the known industries. A new trend for solubilizing phosphate ores (especially the low grade ones) by microorganisms such as fungi and bacteria is developing. This trend is actually encouraged due to environmental and economical concerns. Microbial bioleaching of low-grade deposits makes the industrial application of these ores more economic. This occurs by two means: the first when microorganisms are able to change the redox state of the contained elements rendering them to be more soluble whereas the second when microorganisms attack the ore and release solubility reagents such as organic and inorganic acids that can solubilize these interested economic elements. Vassilev and Vassileva (2003), studied the biotechnological techniques of rock phosphate solubilization processes involving agro-industrial residues. The authors compared between the advantages of composing solid-state fermentation and liquid submerged fermentation employing free and immobilized microorganisms that produce organic acids and simultaneously solubilize the phosphate rock. They stated also that when introducing the fi- nal fermented products into soil, plant systems promote the growth as well as phosphorous acquisition. Over $50 \%$ of the dissolution efficiency of the phosphate ores is achieved by phosphate dissolving microorganisms such as Asperigillus niger, Penicillium sp., Thiobacillus ferrooxidans, Thiobacillus thiooxidans and Rhizobium sacharomyces. A highly significant correlation was found between the numbers of total phosphate-solubilizing fungi and the total phosphorous levels in cultivated and virgin Alberta soils (Kucey, 1983). The solubilization of phosphate from a phosphate containing ore was achieved by Rogers et al., (1993) through treatment with the bacterium Pseudomonas cepacia and the fungi: Aspergillus niger, Aspergillus phenicis, Penicillium sp. and Chrysoporium sp. which allow phosphorous from an aqueous mix of phosphate ore to be recovered.

The main target of this study is the applying microorganisms (fungi and bacteria) which considered as one of the most important and promising nowadays trends for the bioleaching and upgrading of low grade ores such as phosphate ores which have a confirmed reserve in Egypt. Many factors have been studied to achieve nearly complete dissolution of the valuable and strategic elements such as uranium, $\mathrm{P}_{2} \mathrm{O}_{5}$ and REEs.

\section{EXPRIMENTAL}

\section{Material and Methods}

\section{Ore samples}

The ore samples were collected from three Egyptian phosphorite occurrences namely, Nile valley (El Sebaiya locality), Red Sea (Safaga locality) and Western Desert (Abu-Tartur locality) representing the three different commercial phosphate belts present in Egypt.

\section{Chemical composition of the studied phos- phate samples}

Chemical analyses of the major oxides of phosphate rock samples were carried out in 
the laboratories of the Egyptian Nuclear Materials Authority (N.M.A.) according to the method described by Shapiro and Brannock (1962). The major oxides include $\mathrm{SiO}_{2}, \mathrm{Al}_{2} \mathrm{O}_{3}$, $\mathrm{CaO}, \mathrm{MgO}, \mathrm{Na}_{2} \mathrm{O}, \mathrm{K}_{2} \mathrm{O}, \mathrm{MnO}, \mathrm{TiO}$ and $\mathrm{Fe}_{2} \mathrm{O}_{3}$. Trace elements were determined by the $\mathrm{X}$-Ray Fluorescence technique on fused pellets using a Philip X Unique II instrument model PW 1510 and by Flame Atomic Absorption Spectrometry Unicam 969 produced by Unicam Company-England.

\section{Microbial isolates}

The two fungal isolates are used in the dissolution of phosphate rock samples were obtained from the oxidized Abu-Tartur phosphate ore by serial dilution method, in addition to one isolate from the root of wheat plant from El Meniufiya governorate. Bacterial isolate (Pseudomonas fluorescence) was isolated from two locations in Sinai (Abu Thour and Allouga).

\section{Phosphate ore processing}

Phosphate bioleaching experiments were performed by shaking $100 \mathrm{ml}$ of sterilized C'zapeks-dox Broth medium in 250 Erlenmeyer flasks inoculated with $5 \mathrm{ml}$ of stock spore suspension and incubated for 4 days then $0.5 \mathrm{~g}$ of sterilized phosphate rock was added $(0.5 \% \mathrm{w} / \mathrm{v})$ and incubated for another 6 days except otherwise mentioning. After filtration of the bioleaching solution, the soluble $\mathrm{P}_{2} \mathrm{O}_{5}$ was analyzed by the previously mentioned methods.

\section{Application of pyramidal method for phos- phate bioleaching}

The target of applying the pyramidal system in the bioleaching of phosphate rocks by microorganisms was to enrich the leach liquor to the maximum concentration extent as well as to exhaust the treated phosphate rock to the minimal $\mathrm{P}_{2} \mathrm{O}_{5}, \mathrm{U}$ and $\mathrm{REE}$ concentrations. The promotion of the leach liquor concentration was performed by adding new phosphate rock sample to the leach liquor obtained from the previous experiment. However, the exhaus- tion of the $\mathrm{P}_{2} \mathrm{O}_{5}, \mathrm{U}$ and $\mathrm{REE}$ in the treated phosphate rock sample was achieved by the addition of new media (without any organisms) to the leached phosphate rock sample. The leaching experiments were conducted using the obtained optimum conditions while the used fungus was the $A$. niger. After completing the bioleaching experiments, the pulps were filtered and the leached solutions were analyzed for their $\mathrm{P}_{2} \mathrm{O}_{5}, \mathrm{U}$ and REE. The used technique was previously applied by El Hazek and Mahdy (1993), in the liquid-liquid extraction of uranium and in the elution of uranyl carbonate from a strong base anion exchange resin. The pyramidal batch-contact method shown in (Fig. 1) uses a phosphate rock-solution- transfer technique similar to Treybal's counter current contact technique for liquidliquid batch shake-out experiment.

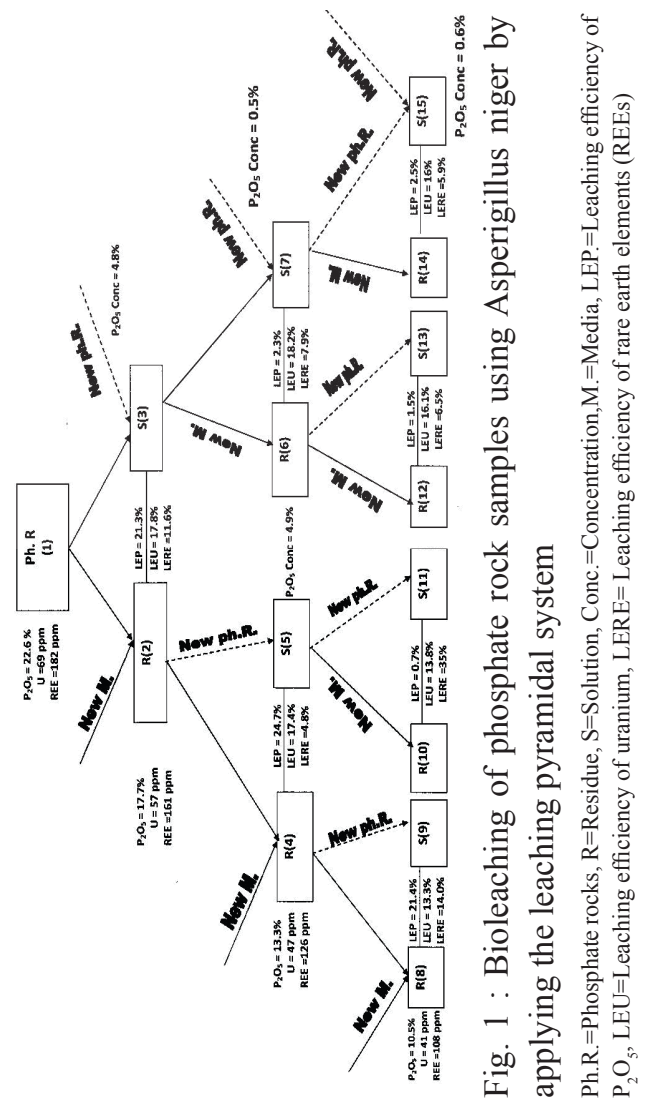




\section{RESULTS AND DISCUSSIONS}

\section{Chemical Characteristics of Phosphate Sample}

Table (1) shows the chemical composition of the phosphate samples obtained from the Nile

Table 1 : Major oxides (\%) of the phosphate rock samples

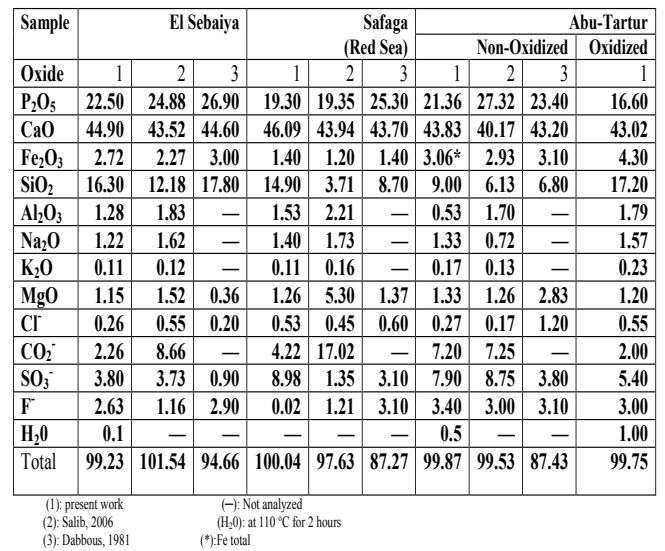

Valley (El Sebaiya), the Red Sea (Safaga) and from the New Valley (Abu Tartur). The trace elements analysis data of the studied phosphate samples are shown in Table (2).

Table 2:Trace elements analysis data (ppm) of phosphate rock samples

\begin{tabular}{|c|c|c|c|c|c|}
\hline \multirow{2}{*}{\multicolumn{2}{|c|}{$\begin{array}{l}\text { Sample } \\
\text { Elements }\end{array}$}} & \multirow[t]{2}{*}{ El Sebaiya } & \multirow{2}{*}{$\begin{array}{r}\text { Safaga (Red } \\
\text { Sea) }\end{array}$} & \multicolumn{2}{|c|}{ Abu-Tartur } \\
\hline & & & & Non-oxidized & Oxidized \\
\hline \multicolumn{2}{|c|}{$\mathrm{U}$} & 69 & 46 & 23 & 32 \\
\hline \multicolumn{2}{|l|}{ Th } & 14 & 10 & 12 & 11 \\
\hline \multicolumn{2}{|l|}{$\mathrm{V}$} & 368 & 123 & 204 & 277 \\
\hline \multicolumn{2}{|l|}{$\mathrm{Cd}$} & 5 & 19 & 11 & 9 \\
\hline \multicolumn{2}{|l|}{$\mathrm{Pb}$} & 10 & 20 & 2 & 13 \\
\hline \multicolumn{2}{|l|}{$\mathrm{Cu}$} & 11 & 24 & 25 & 21 \\
\hline \multicolumn{2}{|l|}{$\mathrm{Cr}$} & 141 & 14 & 72 & 86 \\
\hline \multicolumn{2}{|l|}{$\mathrm{Co}_{0}$} & 4 & 6 & 8 & 11 \\
\hline \multicolumn{2}{|l|}{$\mathrm{Zn}$} & 133 & 142 & 67 & 71 \\
\hline \multicolumn{2}{|l|}{$\mathrm{Sr}$} & 681 & 377 & 40 & 34 \\
\hline \multicolumn{2}{|l|}{$\mathrm{Rb}$} & 24 & 35 & 118 & 66 \\
\hline \multicolumn{2}{|l|}{$\mathrm{Y}$} & 35 & 38 & 78 & 51 \\
\hline \multicolumn{2}{|l|}{$\mathrm{Zr}$} & 37 & 30 & 72 & 63 \\
\hline \multicolumn{2}{|l|}{$\mathrm{Ni}$} & 13 & 4 & 15 & 22 \\
\hline \multirow{3}{*}{$\frac{1}{1}$} & HREE & 61 & 54 & 482 & 313 \\
\hline & LREE & 121 & 119 & 884 & 423 \\
\hline & $\sum$ & 182 & 173 & 1366 & 736 \\
\hline
\end{tabular}

Application of Fungal and Bacterial Isolates for Phosphate Samples Bioleaching

Bioleaching technique has been applied in this study to dissolve the $\mathrm{P}_{2} \mathrm{O}_{5}, \mathrm{U}$ and $\mathrm{REE}$ from phosphate rocks through performing the previously mentioned experiments. Explaining some of the phenomena took place during studying different factors can be briefly presented as follow where the following factors were studied upon Aspergillus niger, Penicillium sp. and Pseudomonas fluorescence. The obtained results from each organism along the studied factors are summarized in Table (3).

Table 3: Factors affecting phosphate bioleaching efficiencies by micro-organisms

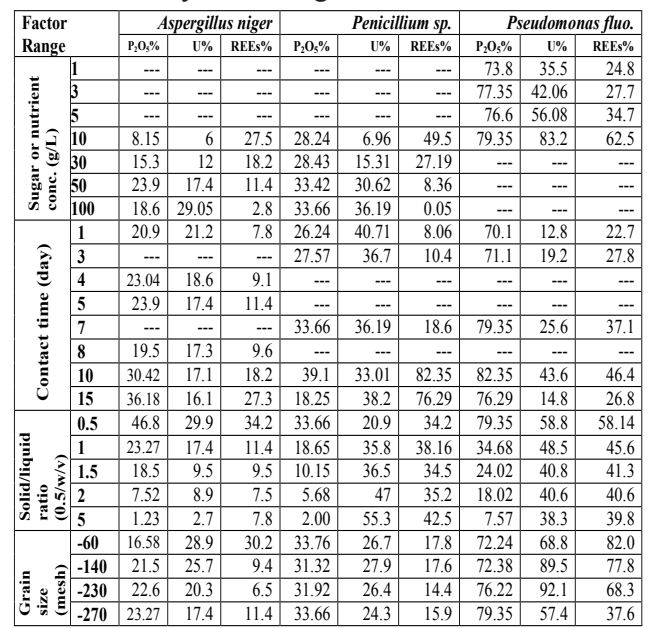

Effect of nitrogen source type on leaching efficiency by Aspergillus niger Fig. (2):

It shows the effect of two nitrogen sources on the phosphate bioleaching efficiency. From the obtained results, it is clear that the ammonium chloride is more favorable as nitrogen source than sodium nitrate in the bioleaching of phosphate rocks. Higher acid production and phosphate solubilization from ammonium assimilation has also been reported for the solubilization of fluoroapatite by Aspergillus niger (Cerezine et al., 1988). It was found that the $U$ and REE bioleaching from the phosphate rock samples using Aspergillus niger had the same trends of the $\mathrm{P}_{2} \mathrm{O}_{5}$ dissolution 
and thus the same interpretations are also applicable here.

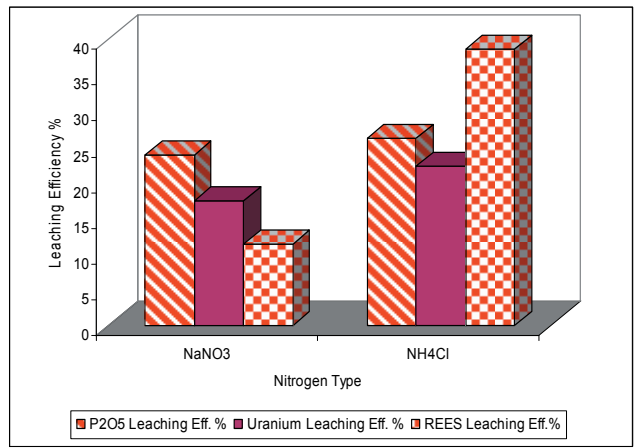

Fig. 2: Effect of nitrogen-source type on leaching efficiency By Aspergillus niger

Effect of carbon source concentration on phosphate leaching efficiency by Aspergillus niger (Fig. 3)

Through studying the effect of carbon source concentration on phosphate leaching efficiency by Aspergillus niger, the solubilization of uranium is attributed to the production of organic acids such as citric acid by the Aspergillus niger fungus. Moreover, the formed weak citric acid plays another important effect. It solubilizes the carbonates of the phosphate rock sample and the latter also increase the dissolution of uranium of the phosphate sample. This organic acid form insoluble salts with solubilized REE.

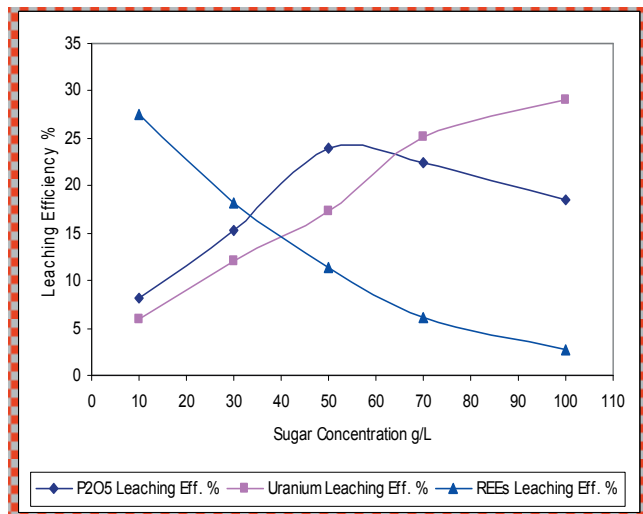

Fig. 3 : Effect of carbon source concentration on leaching efficiency By Aspergillus niger
Effect of carbon source concentration on phosphate leaching efficiency by Penicillium sp. (Fig.4)

It is clear that the phosphate leaching efficiency started with nearly constant leaching value when using 10 and $30 \mathrm{~g} / 1$ sucrose (28.24\% and $28.43 \%$, respectively). After increasing the sucrose up to 50 and $100 \mathrm{~g} / 1$, the leaching efficiency of the phosphate rock samples was increased to $33.42 \%$ and $33.66 \%$, respectively. This increase in the leaching efficiency is actually due to the assimilation of growth rate and further increase in the production of organic acids which decrease the media $\mathrm{pH}$ and thus increasing the solubilization rate of the phosphate rock samples.

When studying the effect of carbon source concentration on phosphate leaching efficiency by Penicillium spinulosum:

- The increase in the U leaching efficiency is in harmony with the increase of the $\mathrm{P}_{2} \mathrm{O}_{5}$ leaching efficiency due to the incorporation and/or substitution of $U$ in apatite phosphate.

- The formed organic acids (especially the oxalic acid) by the action of the microorganism may form REE oxalates precipitates (Mahdy, 1989), thus the soluble REE in leach liquor decreases.

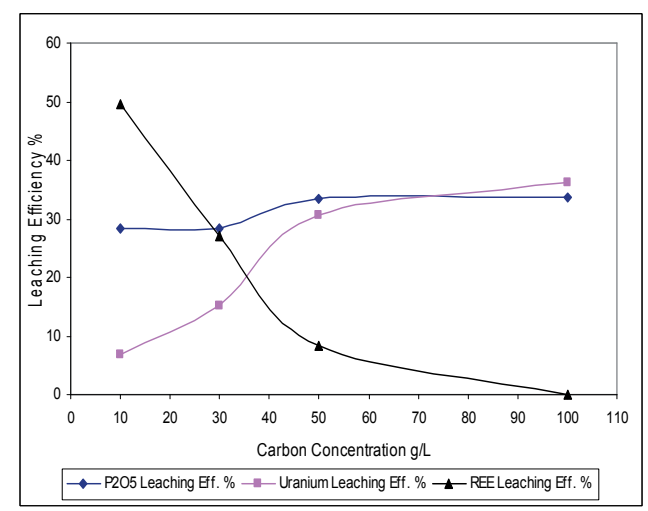

Fig. 4 : Effect of carbon source concentration on Leaching efficiency (using Penicillium Sp.) 
Effect of contact time on leaching efficiency by Aspergillus niger (Fig. 5)

It was clear that the $\mathrm{P}_{2} \mathrm{O}_{5}$ leaching efficiency increased with increasing the incubation time till 5 days reaching $23.9 \%$, the $\mathrm{P}_{2} \mathrm{O}_{5}$ leaching efficiency started to decrease again rapidly till $19.5 \%$ however, another increase (reaching to the optimum $\mathrm{P}_{2} \mathrm{O}_{5}$ leaching efficiency) was recorded at 15 days $36.18 \%$.

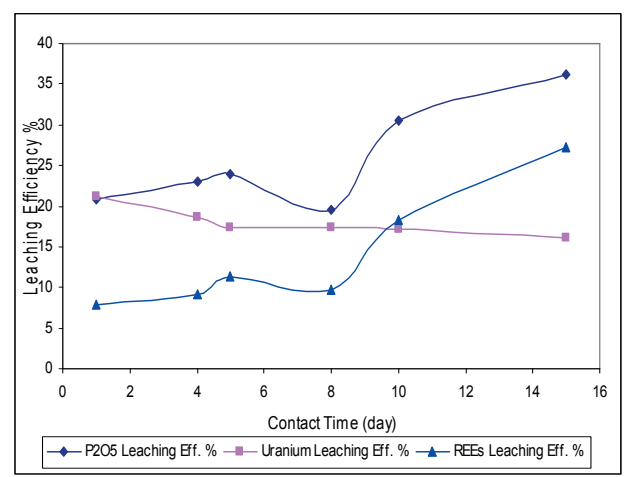

Fig. 5 : Effect of contact time on leaching efficiency by Aspergillus niger

Concerning the bioleaching efficiency of REE from the phosphate rock samples, it follows exactly the $\mathrm{P}_{2} \mathrm{O}_{5}$ leaching however with lower figures. On the other hand, the U bioleaching efficiency from the phosphate rock samples when applying the Aspergillus niger shows almost constant values regardless the incubation time. In other words when increasing the incubation time from one day till 10 days, the leaching efficiency was ranged from 16.1 to $21.2 \%$ only.

\section{Effect of contact time on leaching efficiency by Penicillium sp. (Fig. 6)}

It is clear that the phosphate leaching efficiency increased from $26.24 \%$ to $39.1 \%$ when increasing the incubation time from 1 to 10 days. The phosphate leaching efficiency returns to decrease again at 15 days to $18.25 \%$. This may be due to the organism consumption of the nutrients needed for its survival and growth and consequently to the production of more organic acids, the latter may reach the lag phase of its life cycle. Moreover, the already solubilized salts increase the media $\mathrm{pH}$ and so reduce the phosphate leaching efficiency.

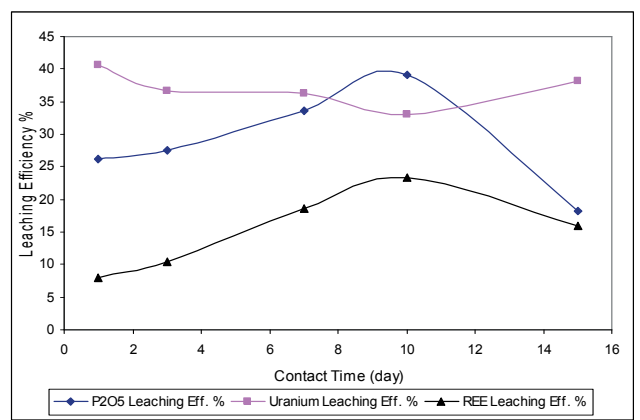

Fig. 6: Effect of contact time on leaching efficiency (using Penicillium Sp.)

The behavior of both $U$ and REE follows the phosphate solubilization trend due to their existence in the crystal lattice of apatite. Or else, the formed organic acids leads to the dissolution of the carbonate constituents of the phosphate rock samples and thus provides more $\mathrm{Ca}++$ to the media to form the insoluble dicalcium phosphate $\mathrm{Ca}\left(\mathrm{HPO}_{4}\right)$ which latter corporate the U and REE.

\section{Effect of grain size on leaching efficiency by Aspergillus niger (Fig. 7)}

It is clear that the smaller particle size is more convenient to bioleaching of the phosphate rock samples due to the increase of their surface area. Thus, it can be seen that the leaching efficiency was slightly constant trend with decreasing the grain size.

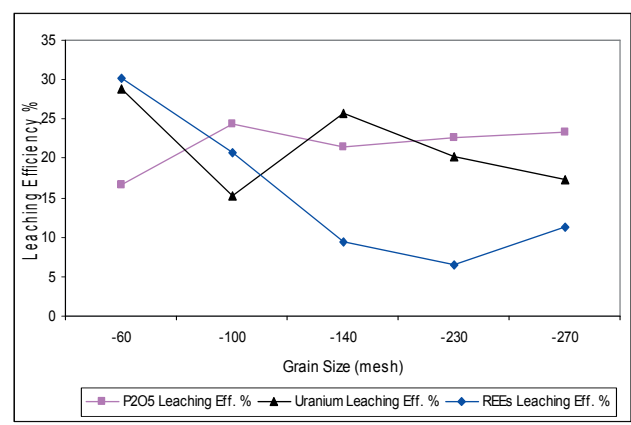

Fig. 7 : Effect of grain size on leaching efficiency By Aspergillus niger 
Effect of solid/liquid ratio on leaching efficiency by Aspergillus niger (Fig. 8)

The leaching efficiency was inversely proportional to the solid/liquid ratio and reached its maximum value at $46.8 \%$ for $0.5 \%$ (sol$\mathrm{id} /$ liquid ratio) then decreased gradually till $1.23 \%$ at $5 \%$ of the ores.

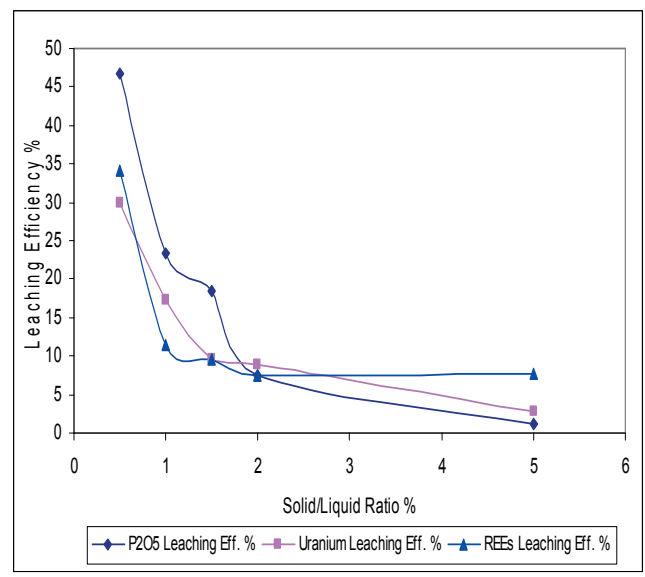

Fig. 8 : Effect of solid/liquid ratio on leaching efficiency by Aspergillus niger

Concerning the bioleaching efficiency of $\mathrm{U}$ and REE from phosphate rock samples when applying the Aspergillus niger. It is clear that both $U$ and REE leaching efficiencies followed the same trend of the phosphate solubilization efficiency due to the existence of the $U$ and REE in the lattice of the phosphate mineral. It is worthy to mention here in that, the amount of the solubilized uranium from its sedimentary ores decrease with increasing the solid/liquid ratio (ore/liquid media ratio) starting from 1\% to $8 \%$ when applying Aspergillus terreus and Penicillium spinulosum (Hefnawy et. al., 2002). The authors attribute the uranium solubilization to following two reasons:

-Raising the final media $\mathrm{pH}$ which perhaps decreases the solubilization efficiency.

-The high binding capacity of the fungal mycelium at higher concentrations of the ore.
Effect of Solid $\backslash$ Liquid Ratio on leaching Efficiency using Penicillium Sp. (Fig. 9)

The decrease in the leaching efficiency of phosphate rock by increasing the solid/liquid ratio is due to the higher concentrations of the rock which may inhibit the growth rate of microorganisms and the further fast death of cells causing decrease in the production of organic acids which is the main topic for the bioleaching mechanism using the fungal isolates.

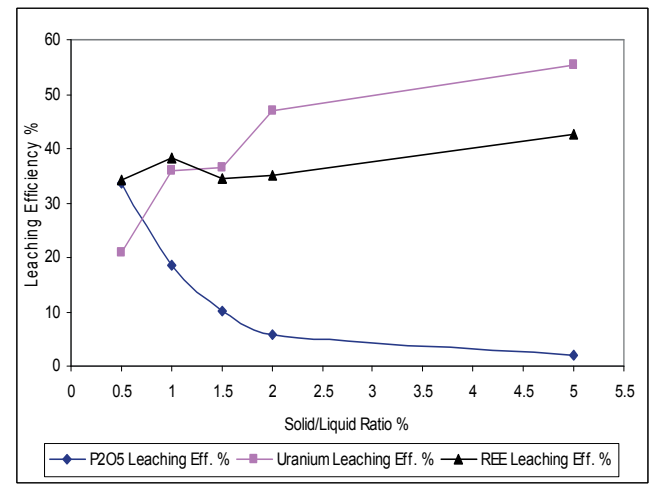

Fig. 9 : Effect of solid \liquid ratio on leaching efficiency (using Penicillium Sp.)

Regarding the effect of solid/liquid ratio on $U$ and REE leaching efficiencies from phosphate rock by applying the Penicillium $s p$., it is clear that by increasing the solid/liquid ratio from $0.5 \%$ to $5 \%$, the U leaching efficiency increased also from 20.9 to $55.3 \%$ (curved line) while the REE leaching efficiency increased slightly from 34.2 to $42.5 \%$ (straight line).

The difference in the behavior of $\mathrm{P}_{2} \mathrm{O}_{5}$ leaching efficiency and both $U$ and REE leaching efficiencies can be attributed to the existence of $U$ and REE in other minerals such as iron oxides minerals and clay minerals in higher concentrations than existing in phosphate minerals. This phenomenon is shown here only due to the libration of these different minerals in different grain sizes. 
Effect of mesh size on leaching efficiency using Penicillium Sp.( Fig. 10)

It is manifested that the grain size has no effect on the leaching efficiency of phosphate rock samples by Penicillium sp. Thus, it can be seen that the leaching efficiency was nearly constant ranging from 31.3 to $33.76 \%$,

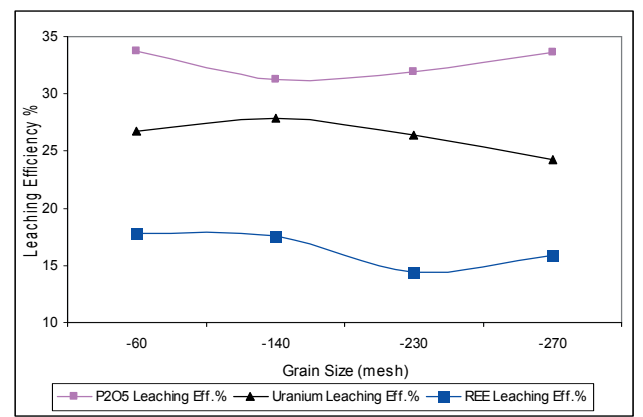

Fig. 10 : Effect of mesh size on leaching efficiency (using Penicillium Sp.)

Concerning the effect of grain size upon U and REE leaching efficiencies from phosphate rock samples by using the Penicillium sp., it is clear that they follow more or less the same trend of the $\mathrm{P}_{2} \mathrm{O}_{5}$ leaching efficiency.

Effect of nutrient concentration (g/l) on leaching efficiency using Pseudomonas fluorescence (Fig. 11)

Effect of nutrient concentration on leaching efficiency by Pseudomonas fluorescence reveals that the leaching efficiency of the phosphate rock samples slightly increases with increasing the beef extract concentration from $1 \mathrm{~g} \backslash 1$ to $10 \mathrm{~g} \backslash 1$ till it reaches maximum value at $79.35 \%$. This increase may be due to increasing of growth rate and production of organic acids, thus decreasing $\mathrm{pH}$ value promotes the leaching efficiency. The same behavior can be traced for both $U$ and REE leaching efficiencies at nutrient beef extract concentration of $10 \mathrm{~g} / \mathrm{l}$. The U and REE leaching efficiencies reached 83.2 and $65.5 \%$ respectively. This is due to the incorporation of $U$ and REE in the crystal lattice of the phosphate minerals or else substituting $\mathrm{Ca}$ in such minerals (Altschuler et. al., 1958).

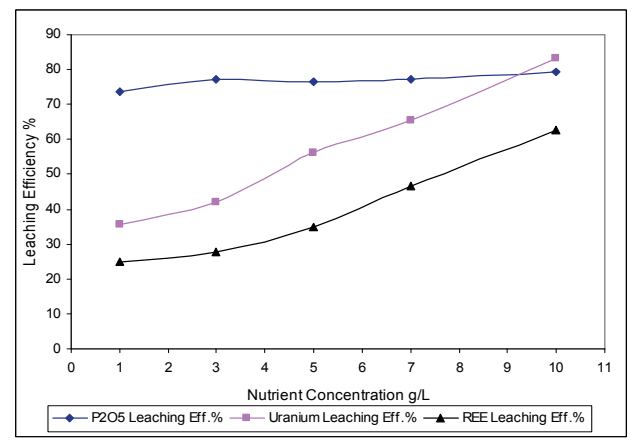

Fig. 11 : Effect of nutrient concentration (g/l) on leaching efficiency (using Pseudomonas fluorescence)

Effect of contact time on leaching efficiency using Pseudomonas fluorescence (Fig. 12)

It is clear that the leaching efficiency of $\mathrm{P}_{2} \mathrm{O}_{5}, \mathrm{U}$ and $\mathrm{REE}$ increased with increasing the period of incubation from 1 day to 10 days till reaching its optimum value at 10 days $(82.35$, 14.8 and $26.8 \%$ respectively). Then it decreased again at 15 days, this may be due to consumption of all the nutrients in the media after this period. Or else, the formed organic acids led to the dissolution of the carbonate constituents of the phosphate rock samples and thus providing more $\mathrm{Ca}^{++}$to the media to form the insoluble dicalcium phosphate $\mathrm{Ca}\left(\mathrm{HPO}_{4}\right)$ then latter corporate the U and REE.

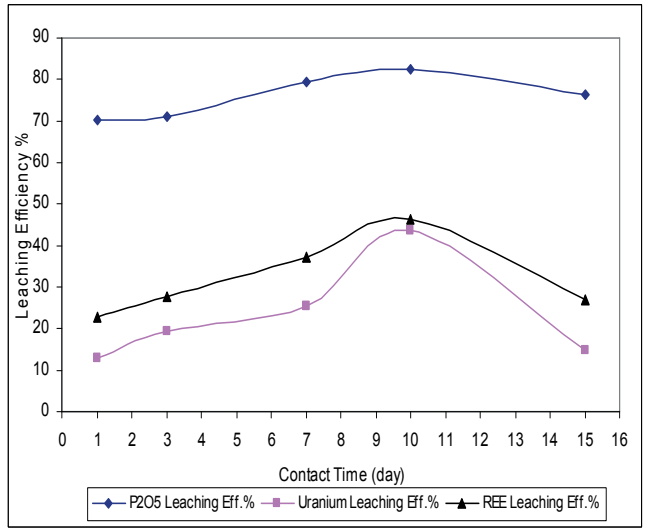

Fig. 12 : Effect of contact time on leaching efficiency (using Pseudomonas fluorescence) 
Effect of solid/liquid ratio on leaching efficiency (using Pseudomonas fluorescence, Fig. 13)

It is clear that the leaching efficiency of phosphate rock samples is inversely proportional to the solid/liquid ratio reaching its maximum $\mathrm{P}_{2} \mathrm{O}_{5}$ higher value at $75.77 \%$ for $0.5 \%$ solid/liquid, then decreased gradually till its maximum $\mathrm{P}_{2} \mathrm{O}_{5}$ lower value at $7.57 \%$ for the higher solid/liquid ratio (5\%).

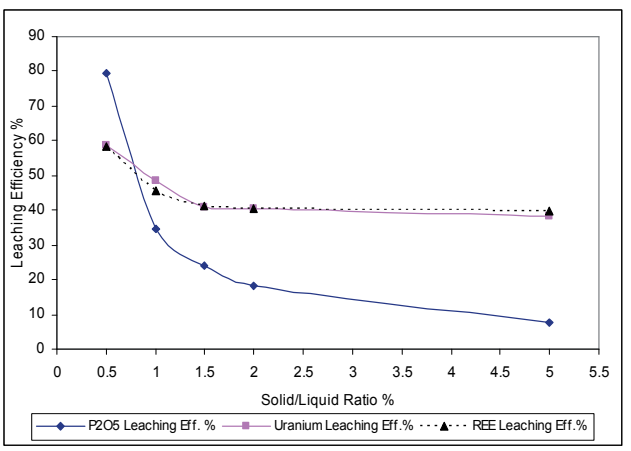

Fig. 13 : Effect of solid/liquid ratio on leaching efficiency (using Pseudomonas fluorescence)

Effect of grain size on leaching efficiency using Pseudomonas fluorescence (Fig. 14)

The obtained data show that the leaching efficiency of phosphate rock samples was increased from $72.27 \%$ to $79.35 \%$ with decreasing the grain size from -60 to -270 meshes. This may be explained according the fact that the decrease in grain size led to the increase in the surface area.

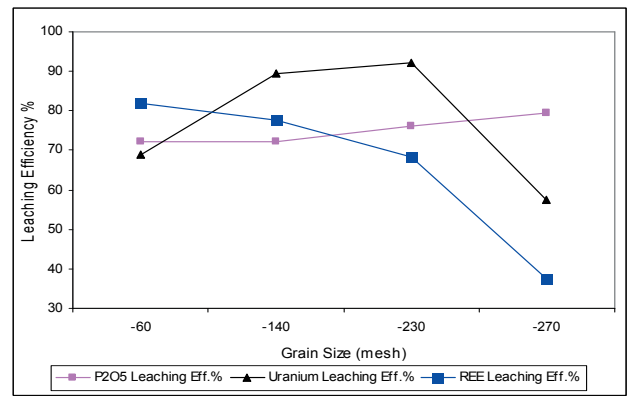

Fig. 14 : Effect of grain size on leaching efficiency (using Pseudomonas fluorescence)
The non-sterilized rock is more favorable than the sterilized one. This may be due to the fact that the addition of the phosphate rock inhibits the growth of the bacteria from the beginning and consequently affect the production of acids and the $\mathrm{pH}$ value of the media which is expressed by decrease of leaching efficiencies.

Application of pyramidal system in bioleaching of phosphate rock, the obtained results of applying this technique are shown in Table 4. The pyramidal system can be applied in the bioleaching of phosphate rock using P. fluorescence bacterial isolate and it is expected that complete $\mathrm{P}_{2} \mathrm{O}_{5}$ leaching could be obtained after applying two cycles.

\section{CONCLUSIONS}

The phosphate rock of Egypt solubilization and some of the contained valuable elements by Aspergillus niger, Penicillium sp. and Pseudomonas fluorescence, have been studied with especial orientation towards the completion of phosphate rock samples solubilization especially the low grade one.

When Aspergillus niger was applied, the optimum leaching of $\mathrm{P}_{2} \mathrm{O}_{5}, \mathrm{U}$ and REE from phosphate rock samples reached $(23.27 \%$, $17.4 \%, 11.4 \%$, respectively).

The optimum conditions for the maximal leaching efficiencies of $\mathrm{P}_{2} \mathrm{O}_{5}, \mathrm{U}$ and $\mathrm{REE}$ when applying the Penicillium $s p$. from the phosphate rock samples were at -270 mesh $33.66 \%, 24.3 \%, 15.9 \%$ respectively, while at 60 mesh they gave $33.76 \%, 26.7 \%, 17.8 \%$ and at -140 mesh gave $31.32 \%, 27.9 \%, 17.6 \%$, respectively.

The optimum conditions for the $\mathrm{P}_{2} \mathrm{O}_{5}$ leaching efficiency when applying the Pseudomonas fluorescence were: $10 \mathrm{~g} / \mathrm{l}$ of beef extract, 10 days incubation period, $0.5 \%$ solid: liquid ratio and -270 mesh of grain size reaching $79.35 \%$. The same behavior was traced for both $U$ and REE leaching efficiencies thus 
they reached $57.4 \%$ and $37.6 \%$, respectively. While the attained results showed that the non sterilized rock is more favorable and the addition of phosphate rock after the incubation of organism for 4 days gave the higher efficiency than the addition of rock at the beginning of experiment.

\section{REFERENCES}

Abd El-Latif, M. M., 1998. Study of the waste material produced from U-Extraction processes of theGattarian Granite and its environmental impact. M. Sc. Thesis, Fac. Sci., Ain Shams Univ.

Altschuler, Z.S., Clarke, R.S. and Young, E.J., 1958. Geochemistry of uranium in apatite and phosphorites, U.S. Geol. Sur., Prof. Paper, 314 D.

Cerezine, P.C., Nahas, E. and Banzatto, D.A., 1988. soluble phosphate accumulation by Aspergillus niger from Fluorapatite, Applied Microbiology and Biotechnology, 29, 501-505.

El Hazek, N.M.T., Mahdy, M.A. and Seidel, D.C., 1993. Characteristics of uranyl carbonate elution from a strong base anion exchange resin, Egypt. J. Analyt. Chem., 2, No. 1, 5-30.

Hefnawy, M.A., El said, M., Hussein, M. and Amin, M.A., 2002. Fungal leaching of uranium from its geological ores in Alloga area west central Sinai, Egypt, On line J. Bioleaching Science, 2, No. 5, 346-350.
Kucey, R.M.N., 1983. Phosphate solubilizing bacteria and fungi in various cultivated and virgin Alberta soils, Canadian J. Soil Sci., 63, 671678 .

Mahdy, M.A and El Shazly, E.M., 1989. Recovery of uranium, thorium and rare earths from acid leach liquor of thorogumite, bastanasite row materials, 2nd Inter. Symp., New Trends in Chemistry, Cairo Univ.

Mahdy, M.A., 2009. Uranium resources in Egypt: Internal Report NMA, Cairo, Egypt.

Nuclear Materials Authority (NMA, Internal Report),1992. The Recovery of Uranium From Phosphoric Acid Produced by Abu- Zaabal Co.

Rogers, Robert, D., Wolfram and James, H., 1993. Microbial solubilization of phosphate, United States Patent, 5, 256, 544.

Shapiro, L. and Bronnock, W.W., 1962. Rapid Analysis of Silicate, Carbonate and phosphate rocks, U.S.G.S., 1144-A, 56 p.

Vassilev, N. and Vassileva, M., 2003. biotechnological solubilization of rock phosphate on media containing agro-industrial wastes, Applied Microbiology and Biotechnology, 61, No. 5-6, 435-440. 


\section{الإذابة الميكروبية لبعض العناصر القيمة من صخر الفوسفات المصرى}

هشام محمد كمال و هبة محمد عبد الحكم و رئيفة أحمد حسنين وخالد فؤاد محمود و محمد عبد المنتصر أبوزيد

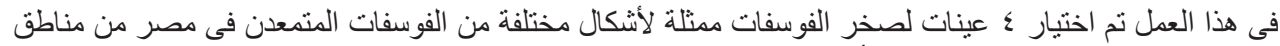

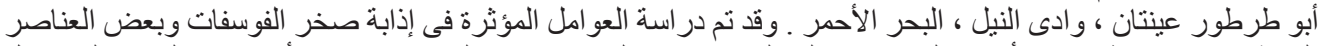

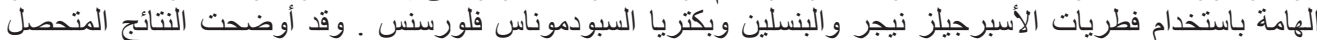

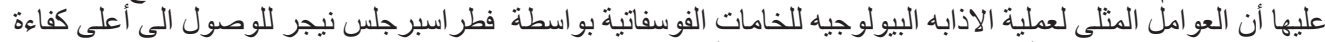

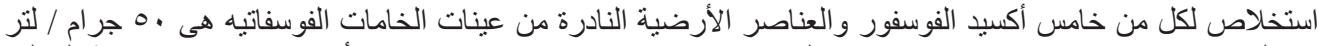

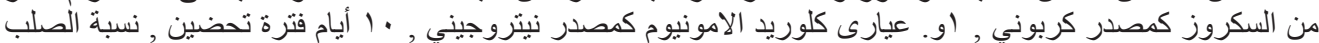

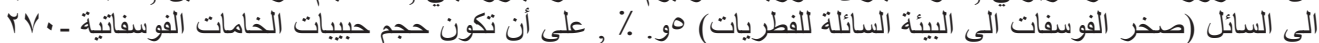

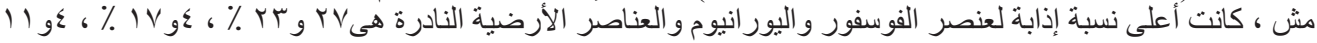

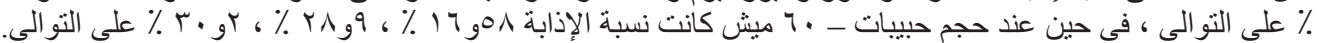

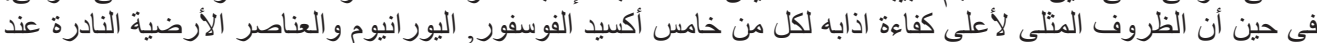

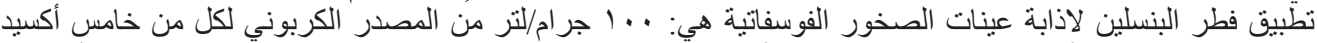

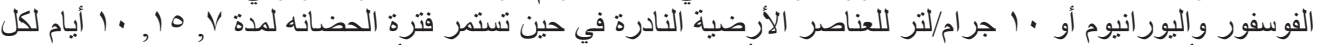

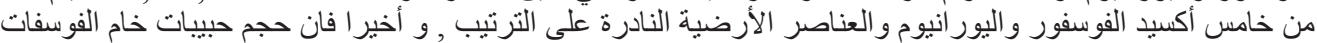

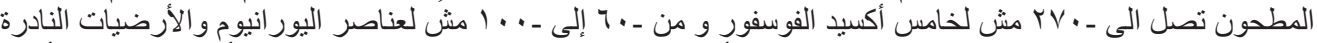

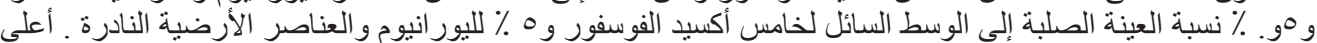

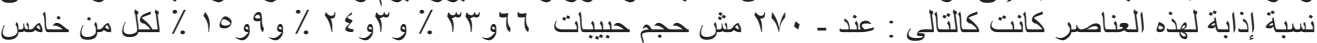

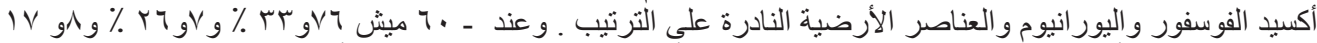

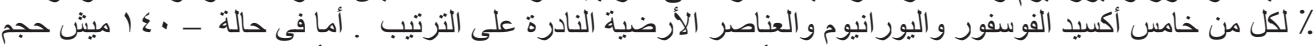

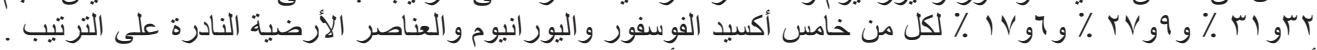

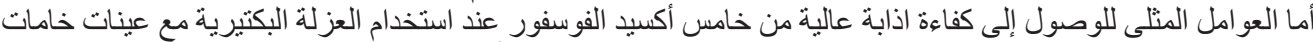

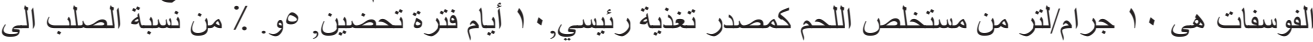

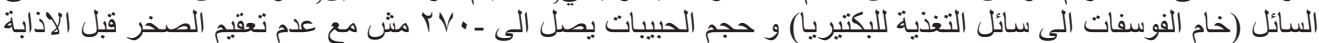

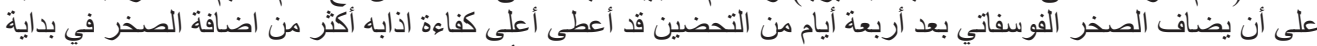

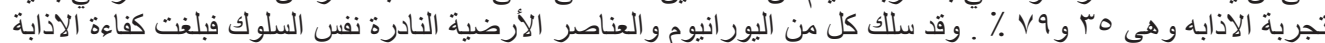

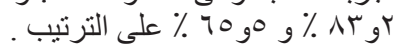

